\title{
Erratum to: Application of isothermal titration calorimetry for evaluation of water-acetone and water-dimethylsulfoxide solvents influence on the molecular complex formation between 18-crown-6 and triglycine at $298.15 \mathrm{~K}$
}

T. R. Usacheva ${ }^{1}$ L. Pham Thi ${ }^{1}$ I. V. Terekhova ${ }^{2}$ R. S. Kumeev ${ }^{2}$. V. A. Sharnin ${ }^{1,2}$

Received: 20 May 2016/Accepted: 21 May 2016/Published online: 13 June 2016

(c) Akadémiai Kiadó, Budapest, Hungary 2016

Erratum to: J Therm Anal Calorim (2015)

121:975-981

DOI 10.1007/s10973-015-4630-0

The correct numeration for $\mathrm{H}-1$ and $\mathrm{H}-3$ peaks is as follows (Fig. 2).
The online version of the original article can be found under doi:10.1007/s10973-015-4630-0.

\section{T. R. Usacheva} oxt@isuct.ru

1 Research Institute of Thermodynamics and Kinetics of Chemical Processes, Ivanovo State University of Chemistry and Technology, pr. Sheremetevski 7, 153000 Ivanovo, Russia

2 G.A. Krestov Institute of Solution Chemistry of the Russian Academy of Sciences, Academicheskaya str. 1, 153045 Ivanovo, Russia

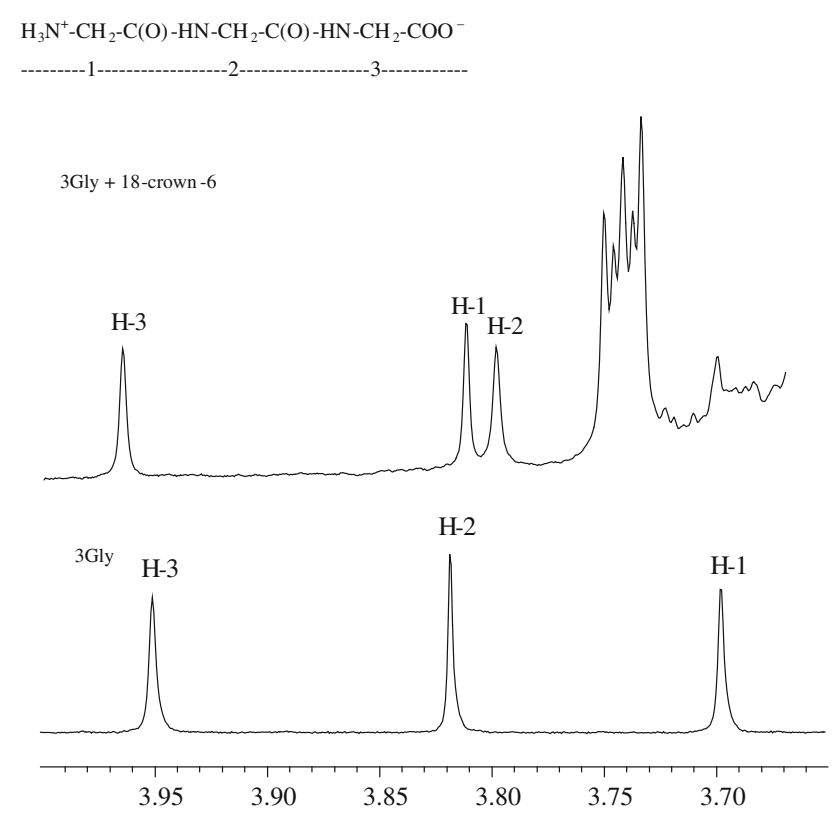

Fig. $2{ }^{1} \mathrm{H}$ NMR spectra of $3 \mathrm{Gly}\left(0.001 \mathrm{~mol} \mathrm{~kg}^{-1}\right)$ in water and solution of 18C6 $\left(0.165 \mathrm{~mol} \mathrm{~kg}^{-1}\right)$ at $T=298.15 \mathrm{~K}$ 